\title{
Caracterização morfodinâmica do litoral Norte Fluminense, RJ, Brasil
}

\author{
(Coastal morphodynamics of the northern Rio de Janeiro State, Brazil)
}

\author{
Alex Cardoso Bastos \& Cleverson Guizan Silva*
}

\author{
Instituto de Geociências da Universidade Federal Fluminense \\ LAGEMAR - Departamento de Geologia \\ (Av. Litorânea s/n, 24210-340 Campus Praia Vermelha, Niterói, RJ, Brasil) \\ *e-mail: cleverson@igeo.uff.br
}

- Abstract: Beach morphology reflects the interaction between hydrodynamic conditions and sediment type. This interaction begins at the wave base, being more effective at the breaker zone where energy is dissipated, originating a surf zone and extending shoreward, up to the swash limit. The goal of this paper is to present the morphodynamic characteristics of the NE littoral of Rio de Janeiro state, showing an analysis based on temporal and spatial variability of beach profiles, morphology of the continental shelf (bathymetric map) and aerial photos. The beach profiles were taken during five years by PETROBRAS (Brazilian 'Petroleum Co.) along 8 different beaches. Differences in morphodynamic behavior along the study coastline are dependent on the interplay among different wave patterns and coastline trends, inner continental shelf morphology controlling the surf zone and the number of breaker zones, sediment grain size and beach face gradient. Four different morphodynamic compartments were recognized based on morphological characteristics of the beach profiles and inner shelf, beach mobility index, sediment size $X$ beach face slope and the $\Omega$ parameter. The four compartments are: a) Atafona/Foz do Rio Paraiba do Sul -intermediate to dissipative morphodynamic state with the highest beach mobility index and a high erosive rate; Sul de Atafona-Cabo de São Tomé -intermediate to reflective state with low beach mobility index; Cabo de São Tomé -reflective to intermediate morphodynamic state with high beach mobility index and Cabo de São Tomé-Cabiúnas -reflective with low beach mobility index.

- Resumo: A morfologia das praias é reflexo da ação hidrodinâmica com o tipo de sedimento disponível. Esta interação se dá a partir da base de ação das ondas, tornando-se mais efetiva na zona de arrebentação onde a energia é dissipada, originando uma zona de surfe que se estende em direção à linha de costa até o limite do espraiamento na face de praia. O objetivo deste trabalho é apresentar as características morfodinâmicas do litoral NE do Estado do Rịo de Janeiro, baseando-se na análise da variação espaço-țemporal de perfis de praia, na morfologia da plataforma continental e em fotos aéreas. Os perfis de praia foram levantados durante cinco anos pela PETROBRÁS S/A, em oito estações ao longo do litoral. $\mathrm{O}$ comportamento morfodinâmico distinto de setores do litoral estudado é função do padrão de ondas e direção da linha de costa, morfologia da plataforma interna controlando a extensão da zona de surfe e o número de zonas de arrebentação, características dos sedimentos e gradiente da face de praia. Foram reconhecidos quatro compartimentos morfodinâmicos distintos, com base na morfologia dos perfis praiais e plataforma interna, no índice de mobilidade da linha de praia, granulometria $x$ gradiente da face de praia e o parâmetro $\Omega$. Os quatro compartimentos são: Atafona/Foz do Rio Paraíba do Sul - estágio morfodinâmico intermediário a dissipativo, com o maior indice de mobilidade e elevada taxa de erosão; Sul de Atafona-Cabo de Sãa Tomé - estágio intermediário a refletivo com baixo índice de mobilidade da praia; Cabo de Sã̃o Tomé -estágio refletivo a intermediário com alto índice de mobilidade da praia; Cabo de São TomếrCabiúnas - estágio refletivo com baixo índice de mobilidade.

- Descriptors: Beach morphodynamics, Shoreline mobility, Beach profile changes, Morphometric parameters.

- Descritores: Morfodinâmica de praia, Mobilidade da linha de costa, Variação temporạl de perfis de praias, Parâmetros morfométricos. 


\section{Introdução}

A evolução costeira, segundo Wright \& Thom (1977), é o produto da morfodinâmica costeira que ocorre em resposta às mudanças nas condições externas, promovendo o ajuste mútuo da topografia e hidrodinâmica, envolvendo o transporte sedimentar. Portanto, o processo morfodinâmico na costa reflete, ao longo do tempo, diferentes padrões de transporte sedimentar e seus produtos deposicionais, que estão controlados pela interação entre topografia e hidrodinâmica (Carter \& Woodroffe, 1995).

A análise morfodinâmica do litoral, isto é, o estudo temporal e espacial das variações morfológicas das praias em associação com as diferentes condições de ondas e tipos de sedimentos, vem tomando uma dimensão muito grande no que concerne à caracterização da estabilidade' e mobilidade das praias. Este tipo de análise objetiva dar subsídios para o desenvolvimento urbano, implantação de estruturas de engenharia e até mesmo qualidade de banho das praias, procurando diminuir o risco de acidentes.

Devido à crescente urbanização e exploração turística das regiões litorâneas e aos impactos ambientais que vêm sendo causados à esta região, o estudo morfodinâmico da costa tornou-se imprescindível para um desenvolvimento sustentável ao longo do litoral. Esta tendência é observada pelos diversos programas que vêm sendo desenvolvidos em vários países, como por exemplo o Australian Beach Safety and Management Program (Short, 1993), Program for the Study of Developed Shorelines (Bush \& Pilkey, 1994), Coastal Risk Assesment Database (Gornitz et al., 1994) dentre outros.

A classificação e descrição morfodinâmica das praias vêm recebendo um novo enfoque a partir principalmente de trabalhos realizados na costa da Austrália. Nos trabalhos publicados por Wright et al (1979 a, b), Short (1981), Wright et al. (1982), Short (1984) e Wright \& Short (1984), os autores integraram fatores morfológicos e hidrodinâmicos e reconheceram 6 estágios morfodinâmicos distintos, sendo dois deles extremos (refletivo e dissipativo) e quatro intermediários. Do ponto de vista morfológico, o estágio dissipativo corresponde a praias planas e rasas com grande estoque de areia na parte submersa, enquanto que o estágio refletivo é caracterizado por praias íngremes com pequeno estoque de areia.

O extremo dissipativo pode ser comparado morfologicamente aos perfis de tempestade em praias com variação sazonal. É um perfil aplainado, geralmente composto de areia fina e gradientes suaves, geralmente apresentando extensa zona de surfe e mais de uma linha de arrebentação o que caracteriza a ocorrência de vários bancos paralelos.

O estágio extremo refletivo é caracterizado por perfis com a face de praia bastante íngreme e as ondas comumente quebram diretamente na face de praia, causando uma maior velocidade de espraiamento. As praias refletivas geralmente desenvolvem cúspides ou alinhamento de cristas de berma elevadas, sendo compostas por areias grossas e são também mais instáveis à erosão em função do aumento da energia das ondas.

Os quatro estágios intermediários apresentam maior complexidade morfológica e hidrodinâmica e caracterizam-se por praias com grande mobilidade, onde ocorrem seqüências acrescionais, como megacúspides e bancos longitudinais.

Utilizando-se esta classificação morfodinâmica espera-se caracterizar os diferentes setores do litoral norte do Estado do Rio de Janeiro, mais especificamente o trecho entre Cabiúnas e Atafona, quanto ao aspecto morfológico das praias e seu estado morfodinâmico modal, identificando suas variações temporais e indicando assim áreas de maior ou menor mobilidade dos perfis, com tendências erosivas ou de progradação. Este litoral, dentro do Estado do Rio de Janeiro, tem sua importância econômica e social ressaltada em virtude da exploração de hidrocarbonetos na plataforma continental adjacente pela PETROBRÁS, acarretando na chegada de oleodutos em vários pontos do litoral. Além disso, ocorrem cidades balneários como Farol de São Tomé, Grussaí, Barra do Furado e Atafona e destaca-se a atividade pesqueira desenvolvida pelas comunidades destas cidades.

\section{Área de estudo}

\section{Planície Costeira}

A área de estudo compreende basicamente o litoral norte fluminense, entre os distritos de Atafona, ao norte, e Cabiúnas ao sul. (Fig. 1).

A planície costeira do rio Paraíba do Sul, conhecida como Baixada Campista, está localizada na porção terrestre da Bacia de Campos, com uma área de $2500 \mathrm{~km}^{2}$ estendendo-se para o interior até o contato com o complexo cristalino ou com depósitos terciários do Grupo Barreiras. 


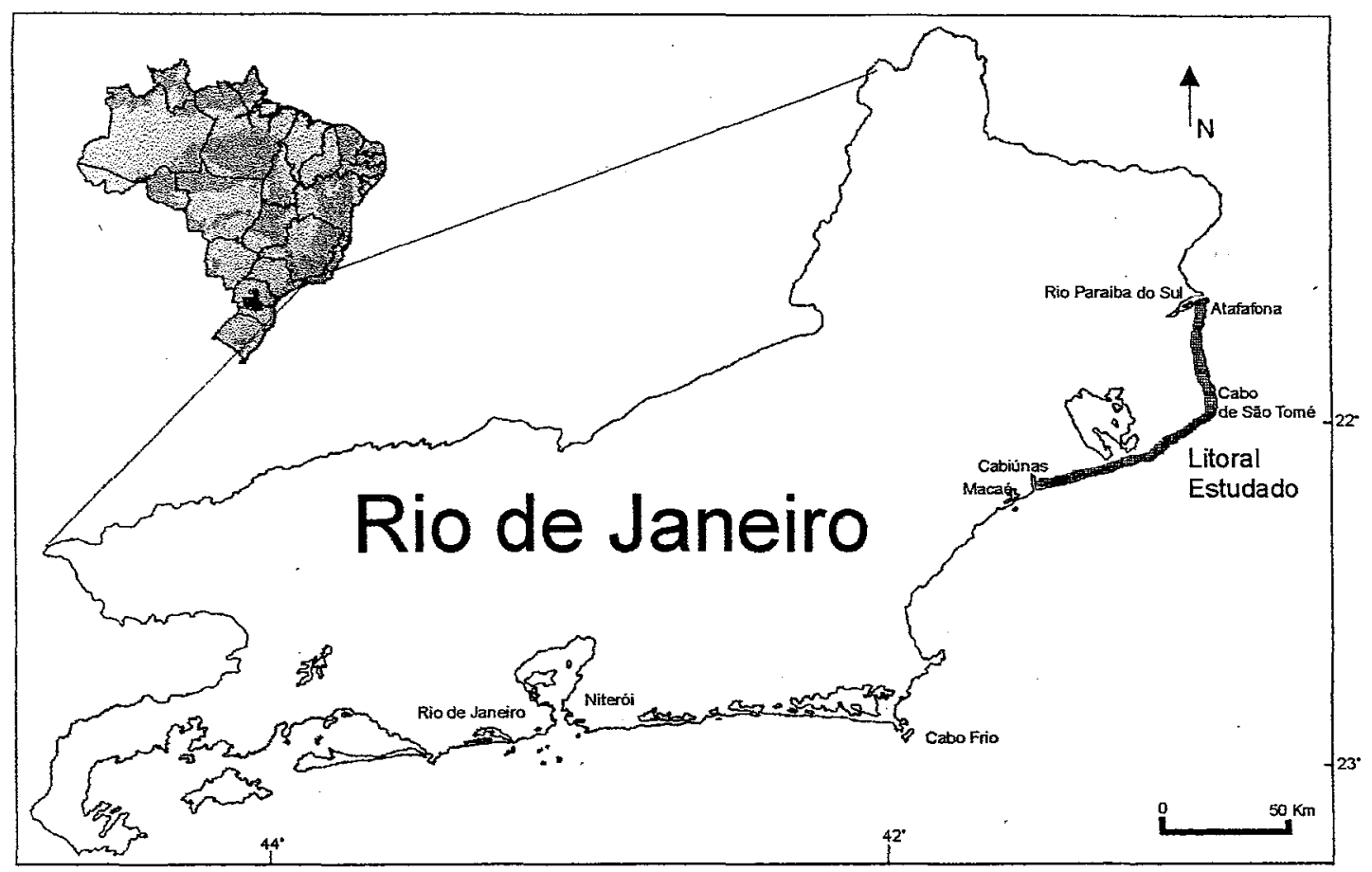

Fig. 1. Mapa de localização da área de estudo.

Silva (1987) divide a planície costeira, ou complexo deltaico, em duas regiões com características morfológicas e estratigráficas distintas (Fig. 2): a) litoral progradante em forma de cúspide, entre Porto de Manguinhos e Cabo de São Tomé, formado por sucessivas cristas de praia que marcam o contínuo avanço do continente sobre o mar; b) litoral retrogradante entre o Cabo de São Tomé e Macaé, onde um cordão arenoso transgressivo vem se deslocando em direção ao continente, truncando lagunas costeiras e antigos sistemas de cristas de praia associados ao antigo curso do rio Paraíba do Sul.

Martin \& Suguio* (1989), propõem uma correlação entre o padrão de anomalias gravimétricas com a morfologia costeira, assim como Silva et al. (1997) associam as características morfológicas e estratigráficas da planície costeira do rio Paraíba do Sul, a um comportamento tectônico diferenciado ao longo do litoral do Estado do Rio de Janeiro. Estes autores observam que o litoral retrogradante entre Macaé e Cabo de São Tomé está associado a anomalias gravimétricas negativas, em áreas onde a linha de charneira das Bacias de Campos e Santos, se afastam do litoral.

(*) Martin, L. \& Suguio, K. 1989. Excursion route along the brazilian coast between Santos (State of São Paulo) and Campos (North of State of Rio de Janeiro). In: INTERNATIONAL SYMPOSIUM ON GLOBAL CHANGES IN SOUTH AMERICA DURING THE QUATERNARY. São Paulo, 1989. Resumo. São Paulo, ABEQUA/INQUA, 2:136p.
Por outro lado, ao norte do Cabo de São Tomé, o litoral progradante, caracterizado pela planície de cristas de praia adjacente à desembocadura do rio Paraiba do Sul, acha-se associado a anomalias gravimétricas positivas, onde a linha de charneira da Bacia de Campos ocorre próximo ao litoral.

\section{Plataforma continental}

A morfologia da plataforma continental é um dos fatores condicionantes nas diferentes características morfodinâmicas da costa, influenciando o padrão de propagação das ondas que resultam em diferenças no comportamento das praias. Estas variações estão associadas ao gradiente, largura, morfologia e tipo de fundo da plataforma continental, que condicionam a transformação das ondas que se propagam em águas rasas, provocando refração e difração das ondas (Calliari \& Klein, 1993).

Sendo assim, foi feita uma caracterização morfológica da plataforma continental entre Itapemirim e Cabo Frio, utilizando-se o mapa batimétrico detalhado, com isóbatas de 5 em $5 \mathrm{~m}$ (Fig. 3).

Observa-se que ao largo de Cabo Frio as isóbatas se encontram bastante próximas, sendo que em direção E-NE, ocorre não só uma mudança na direção do litoral, que passa a ser NE-SW, como também ocorre um alargamento da plataforma continental. 


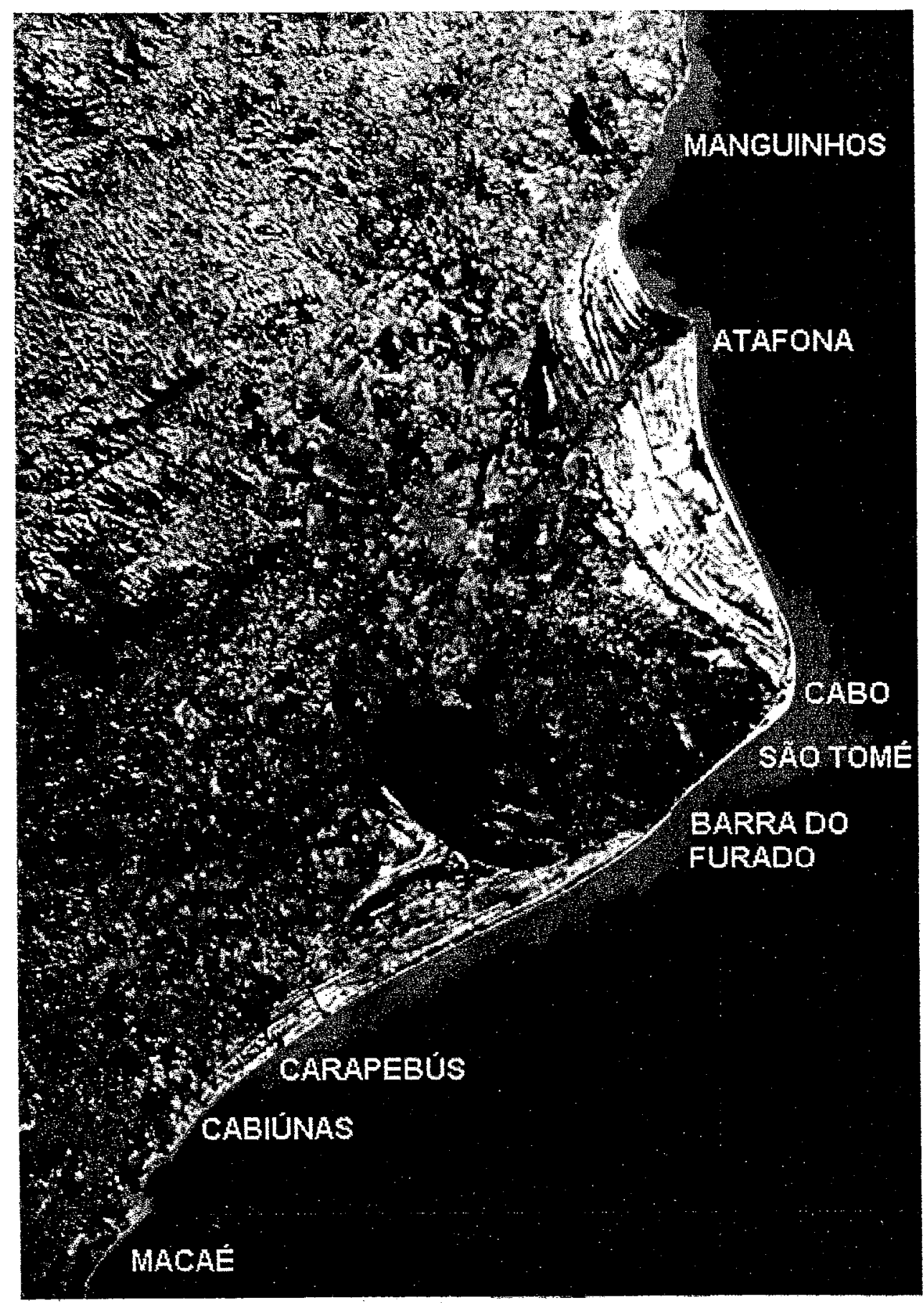

Fig. 2. Imagem de satélite da planície costeira e do litoral entre Macaé e Manguinhos. 


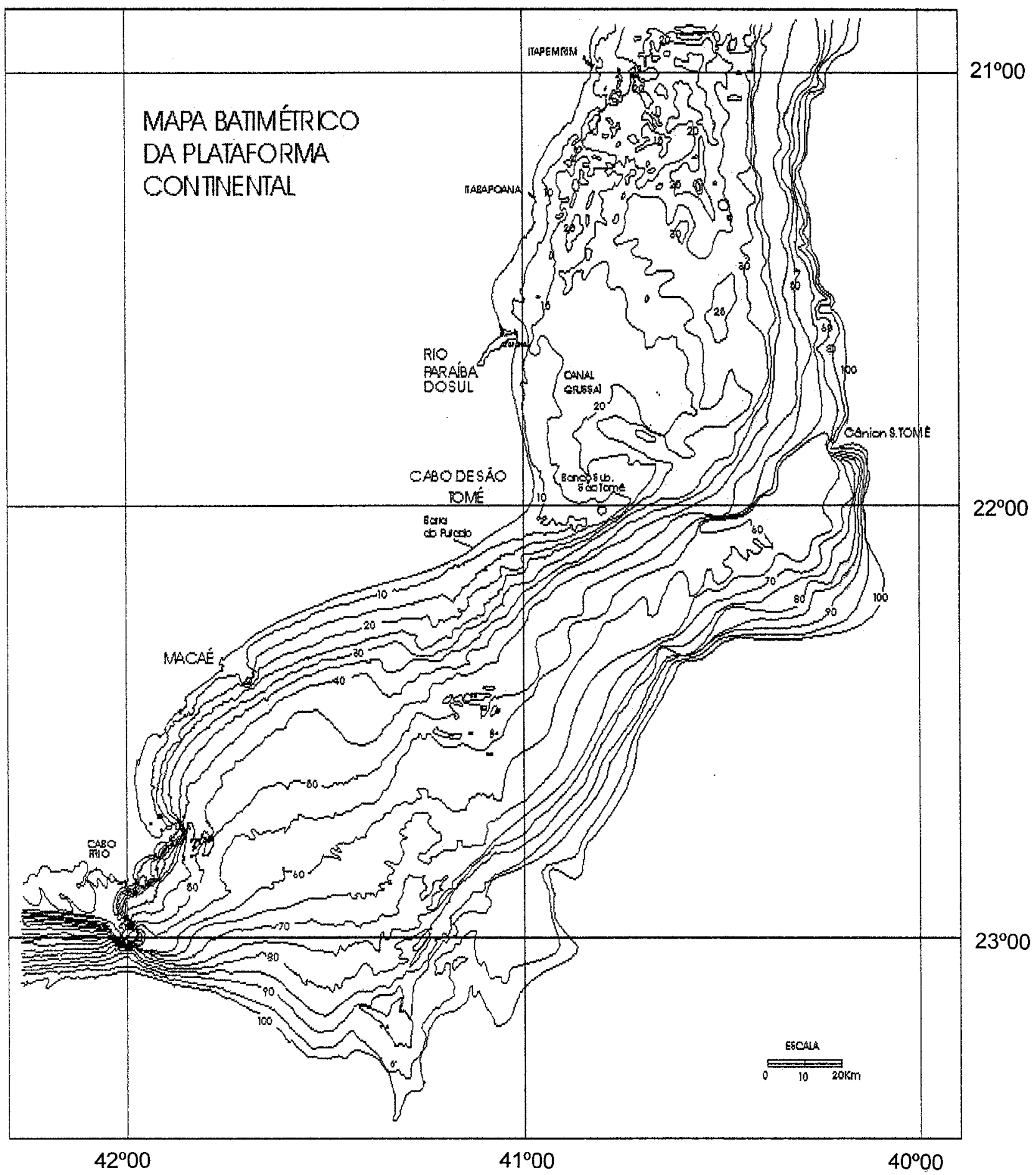

Fig. 3. Mapa batimétrico da plataforma continental adjacente ao litoral norte fluminense. (Projeção UTM, Meridiano central -39).

Seguindo para norte, observa-se ao largo do Cabo de São Tomé um banco submarino marcado pelas isóbatas de 10 e $15 \mathrm{~m}$ que se estende por cerca de $21 \mathrm{~km}$ ortogonalmente à costa, sendo denominado de Banco de São Tomé.
Ao norte do Cabo de São Tomé ocorre uma mudança na direção da linha de costa, que passa a ser NNW-SSE, e um alargamento da plataforma continental interna, compreendida até $30 \mathrm{~m}$ de profundidade. 
Contrastando ao aspecto morfológico descrito ao sul do cabo, observa-se que a plataforma interna ao largo do litoral, entre Cabo de São Tomé e a foz do Rio Paraíba do Sul, é caracterizada por uma morfologia relativamente plana com baixo gradiente em torno de 1:2.200. Nesta porção, a feição mais conspícua observada foi o registro de um paleocanal, denominado Canal de Grussaí, de direção NW-SE e delineado pelas isóbatas de 20 e $25 \mathrm{~m}$.

De acordo com Alves \& Ponzi (1984), a distribuição de sedimentos superficiais ao longo da plataforma interna entre Itabapoana e Cabo Frio é predominantemente terrígena, representada por areias quartzosas com baixo teor de carbonatos, excetuando-se a região ao largo de Itabapoana, onde predominam sedimentos carbonáticos. A região da plataforma externa é caracterizada pela ocorrência de sedimentos carbonáticos, representados principalmente por algas calcáreas nodulares e ramificadas.

\section{Ventos, Ondas, Maré e Transporte Litorâneo}

As medições de direção e intensidade de ventos obtidas pela Diretoria de Hidrografia e Navegação (DHN), na localidade de Farol de São Tomé durante o ano de 1992, indicam ventos mais freqüentes a partir do quadrante $\mathrm{NE}$ com velocidades em torno de $2,6-5,1 \mathrm{~m} / \mathrm{s}$ em média.

A caracterização do regime de ondas pode ser feita mediante os dados do levantamento realizado por Souza (1988) a partir de ondógrafos posicionados na plataforma de Garoupa (PGP-1) localizada na plataforma continental da região da Bacia de Campos, litoral nordeste do Estado do Rio de Janeiro. A profundidade no local é de cerca de $130 \mathrm{~m}$.

Ao longo do ano, a maior freqüência da direção de incidência de ondas está associada a ventos locais dos quadrantes $\mathrm{NE}$ e $\mathrm{E}$, ocorrendo ainda ondas provenientes dos quadrantes SE, S, SW, associadas à frentes frias.

Quanto à altura das ondas (Ho), observa-se uma altura média compreendida entre $1,6 \mathrm{e} 2,0 \mathrm{~m}$. Observou-se ainda que as ondas com alturas superiores a 3,0 m são mais freqüentemente oriundas dos quadrantes $\mathrm{S}$ e SW.

Embora ocorra uma frequiência bastante superior das ondas de NE e E, quando comparada à distribuição de energia das ondas por direção de incidência e por mês, observamos que as ondas de SSE, S e SSW embora pouco freqüentes, são as que concentram maior energia (Fig. 4, Muehe \& Correa, 1989).

Segundo informações da DHN para a Ponta de Imbetiba em Macaé, a variação de maré alcança $1,3 \mathrm{~m}$ em maré alta de sizígia e $0,3 \mathrm{~m}$ em maré baixa.
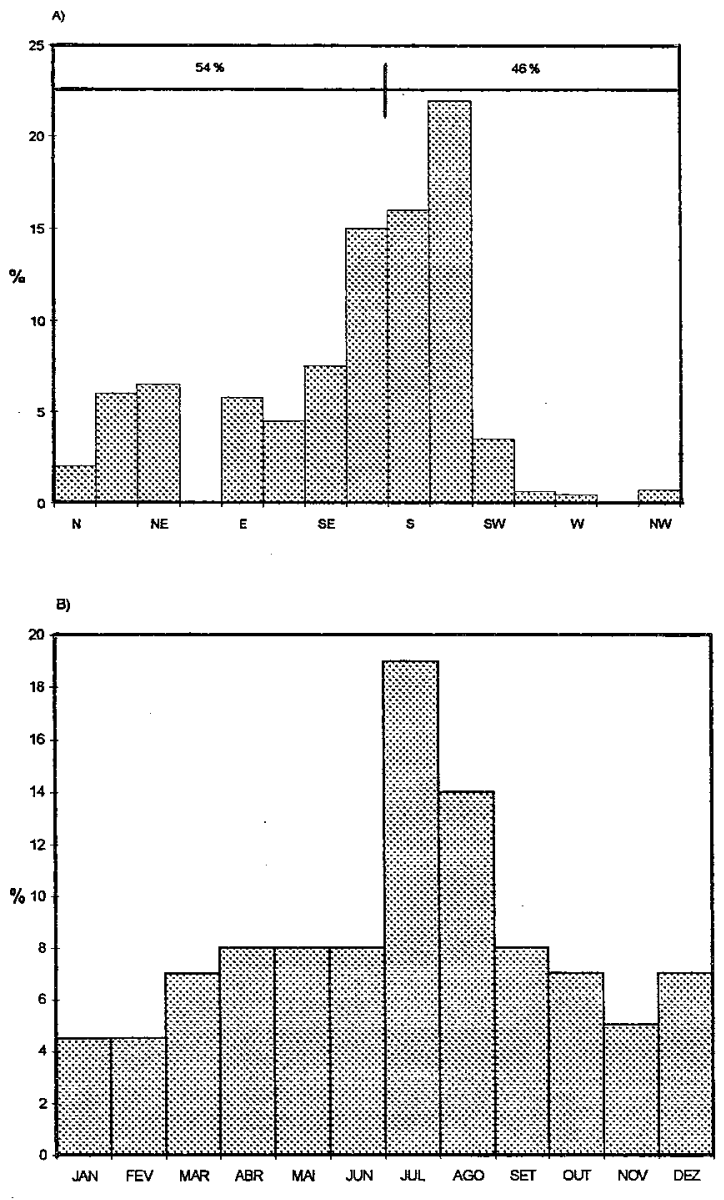

Fig. 4. Distribuição percentual das ondas por direção de incidência (a) e por mês (b). (Souza, 1988 apud:Muehe e Correa, 1989).

Cassar \& Neves (1993), utilizando a metodologia de rosas de transporte litorâneo, propõem a quantificação do transporte litorâneo sedimentar para o litoral norte fluminense, calculado para 8 pontos do litoral, desde Barra do Furado até Itabapoana. Os resultados obtidos são mostrados na Figura 5.

No contexto do litoral estudado, Cassar \& Neves (op. cit.) apontam que o transporte residual ao longo do ano, na região de Atafona e Grussaí, se dá em direção sul. Em contrapartida, os autores mostram que o transporte ao longo do litoral entre Barra do Furado e Cabo de São Tomé, é preferencialmente em direção norte.

Dominguez et al. (1983) e Martin et al. (1984a) acreditam que o transporte principal de sedimento seja no sentido $\mathrm{S}-\mathrm{N}$ e demonstram esta proposta com base no molhe construído na Barra do Furado, litoral sul, onde $\mathrm{o}$ aprisionamento de sedimento se dá ao sul do molhe. Martin et al. (1984b) também justificam esta hipótese com base na análise morfoscópica de grãos de areia ao sul e ao norte da desembocadura. 


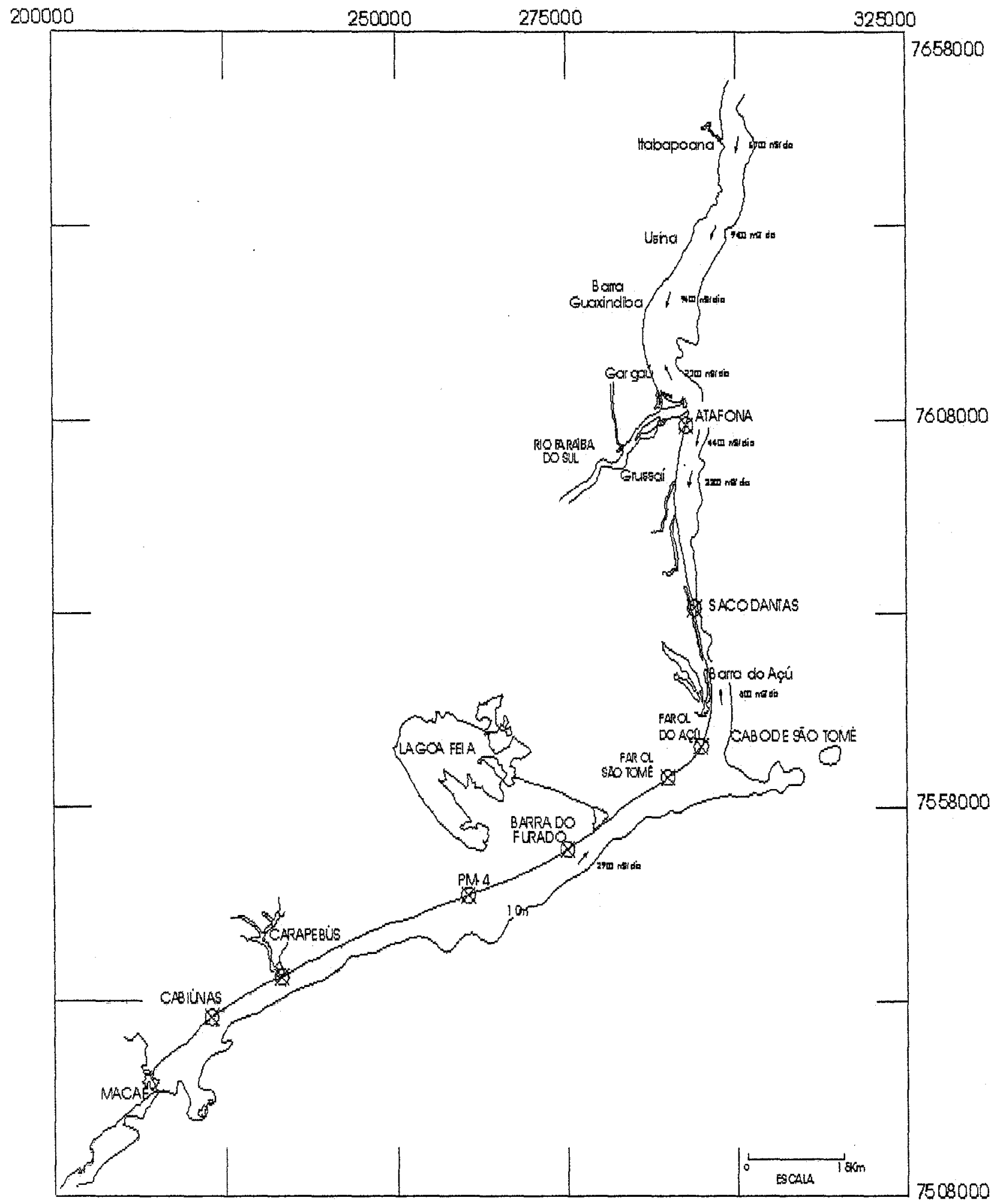

Fig. 5. Mapa indicando o sentido do transporte litorâneo ao longo do litoral norte fluminense por Cassar \& Neves (1993), e a localização das estações de perfilagem ao longo do litoral. (Projeção UTM, Meridiano Central-39). 


\section{Métodos}

O estudo da dinâmica costeira atual foi efetuado através de perfis de praia e dados bibliográficos. Desde 1989, a Petrobrás, através da Gerência de Geologia Marinha (GEOMAR) lotada em Macaé, vem coletando dados de topografia de praia em 8 estações entre o litoral de Atafona e Cabiúnas (Fig. 5). Estes dados foram cedidos pela PETROBRÁS, passando então a serem processados e analisados no LAGEMAR-UFF.

O levantamento topográfico dos perfis foi realizado por meio de teodolito, apenas no prisma praial emerso, até a linha de recuo das ondas, onde foram coletadas amostras na face de praia. Inicialmente o plano de intervalo dos levantamentos seria mensal, porém, por problemas logísticos, não foi possível uma amostragem mensal durante todo o período de levantamento. Os perfis foram levantados no período de dezembro de 1989 até fevereiro de 1995, totalizando 20 levantamentos na localidade de Atafona, $23 \mathrm{em}$ Saco Dantas, 24 no Farol do Açú, 24 no Farol de São Tomé, 25 em Barra do Furado, 24 na estação PM-4, 20 em Carapebús e 13 em Cabiúnas. O menor número de levantamentos em Cabiúnas deve-se à mudança da posição do perfil durante o período de levantamentos, o que fez com que, para este trabalho, fossem utilizados apenas os dados da série histórica entre dezembro de 1989 a junho de 1991 disponíveis para a localidade de Cabiúnas.

A partir destes perfis procurou-se descrever as características morfodinâmicas dos diferentes pontos de acordo com a terminologia e os parâmetros morfométricos propostos por Wright \& Short (1984), Short \& Hesp (1982) e Klein (1997) adaptados para a área de estudo por Bastos (1997).

Vale ressaltar, que os dados a cerca das condições do clima de ondas foram obtidos a partir do levantamento bibliográfico, logo se tratam de valores médios de altura e período de ondas, extrapolados para o litoral norte-fluminense. Portanto, o valor calculado para $\Omega$ a partir da equação de Dean (1973) não representa um valor modal, e sim, um valor médio que reflete as condições mais comuns no que tange o comportamento das ondas

Com o intuito de se avaliar as variações volumétricas entre os perfis de praia, foi usado o Interactive Survey Reduction Program (ISRP, Birkemeier, 1985) idealizado para o U.S. Army Corps of Engineers. Este programa oferece uma comparação entre dois perfis, estimando o volume de sedimento erodido e depositado acima de um datum,

- e também o deslocamento da linha de praia (Bastos, 1994). O volume calculado expresso em $\mathrm{m}^{3} / \mathrm{m}$ corresponde à área da seção transversal multiplicada por uma unidade de largura $(1 \mathrm{~m})$.

Os valores de variação de volume e deslocamento da linha de praia foram calculados a partir de perfis consecutivos, e objetivando a comparação entre as diferentes estações de perfilagem, foram obtidos valores comparativos simples e valores acumulados para cada estação ao longo do levantamento. Vale ressaltar que os valores adquiridos neste programa, embora sejam absolutos, têm um caráter mais qualitativo/comparativo.

\section{Perfis de praia Atafona}

O perfil em Atafona é caracterizado morfologicamente pela erosão frontal do campo de dunas, exibindo uma falésia com cerca de $3 \mathrm{~m}$ de altura, que é marcante ao longo do litoral na localidade de Atafona. O perfil de praia apresenta em média uma largura de $150 \mathrm{~m}$, com uma face de praia com declive de $1: 11\left(5,1^{\circ}\right)$ e composta por areia média $(0,420 \mathrm{~mm} / 1,2 \phi)$.

A análise da variação temporal dos perfis de praia (envelope) pode ser observada na Figura 6, destacando-se não só a grande mobilidade do perfil, mas principalmente a tendência de recuo da linha de costa. Esta tendência é corroborada no gráfico da Figura 7 que mostra a variação da largura do perfil da praia. A partir deste mesmo gráfico, obteve-se o índice de mobilidade da linha de praia (Short \& Hesp, 1982), alcançando o valor $\sigma \gamma b=19$, caracterizando assim o alto grau de mobilidade deste perfil, que é o mais elevado comparando-se com o restante dos perfis ao longo do litoral. Observou-se que após 5 anos de levantamentos, a linha de praia recuou cerca de $37 \mathrm{~m}$ definindo uma taxa média de recuo de 7 a $8 \mathrm{~m} /$ ano para Atafona.

Embora ocorra em Atafona uma grande variação no volume de sedimentos remobilizados ao longo da pesquisa, ao se considerar a variação volumétrica acumulada ao longo do período dos levantamentos, não há uma tendência à perda ou ganho de sedimentos. Este aspecto pode ser explicado pela ação efetiva dos processos eólicos na região, evidenciado pelo alto índice de mobilidade do pós-praia $(\mathrm{CV}=13 \%)$. Logo, existe um balanço indireto entre o volume de sedimentos erodidos na face de praia e o volume associado aos processos eólicos no campo de dunas.

Assim sendo, a praia de Atafona é influenciada pela dinâmica de sedimentação da foz do rio Paraíba do Sul e por uma atividade eólica intensa, apresentando um alto índice de mobilidade. Esta praia pode ser descrita e classificada como possuindo características intermediárias, como mostram os valores de $\Omega$ e $\Omega$ teórico na Tabela 1 . 

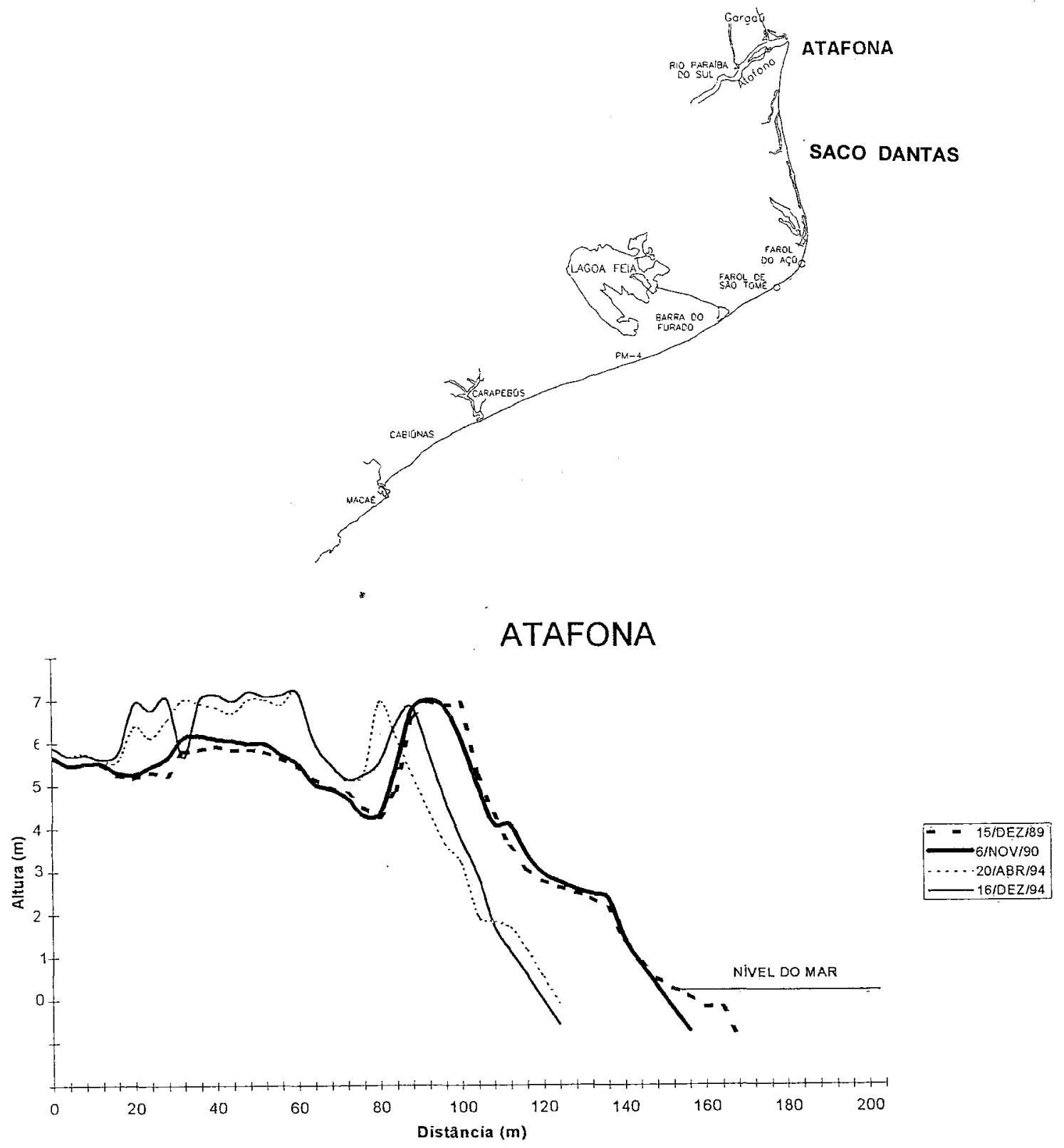

SACO DANTAS

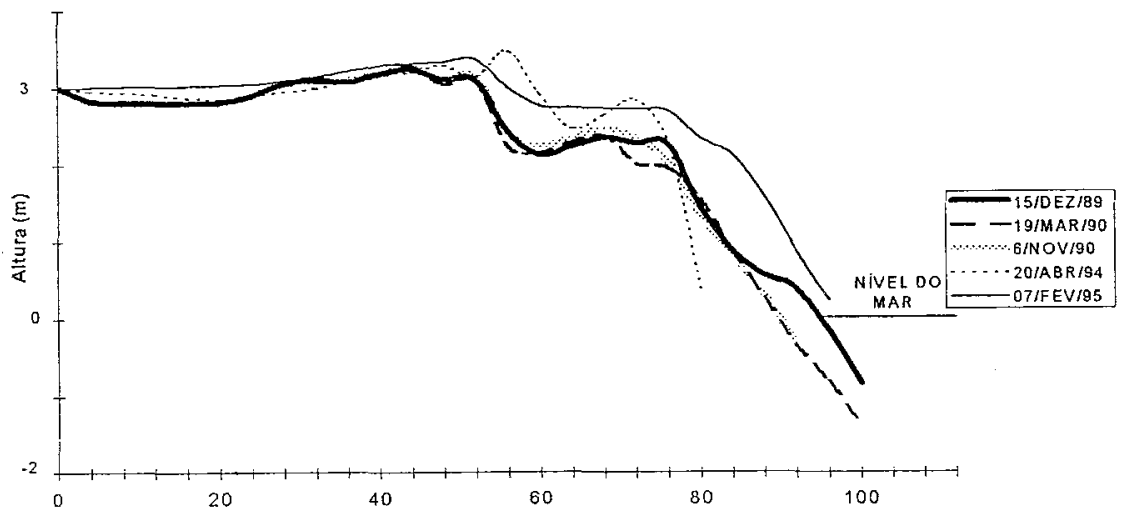

Fig. 6. Envelope de variação temporal dos perfis de praia em Atafona e Saco Dantas. 

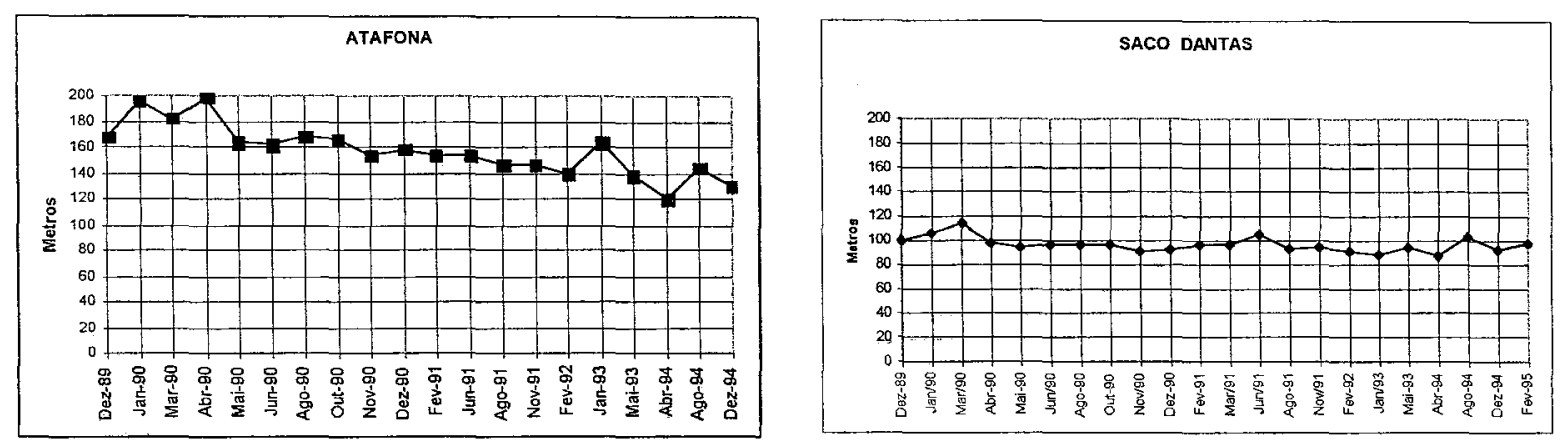

Fig. 7. Gráfico da variação temporal da largura da praia em Atafona e Saco Dantas.

\section{Saco Dantas}

Morfologicamente, o perfil em Saco Dantas é caracterizado por um pós-praia plano com gradiente suave, delimitado por uma ou duas cristas de berma seguido de uma face de praia relativamente íngreme, com declive de $1: 8\left(7,5^{\circ}\right)$ e composta por areia grossa $(0,720 \mathrm{~mm} / 0,45 \phi)$. A largura média do perfil praial é de $96 \mathrm{~m}$.

Uma das principais características da variação temporal dos perfis neste ponto são os baixos índices de mobilidade da linha de praia, $\sigma \gamma \mathrm{b}=6$, e do pós praia, $\mathrm{CV}=0,06(6 \%)$, que podem ser visualmente interpretados através dos gráficos de variação temporal e da largura dos perfis de praia (Figs 6 e 7 , respectivamente).

Quanto à variação acumulada de volume sedimentar, embora exista uma tendência ao ganho de volume, as variações volumétricas também foram relativamente pequenas, corroborando o baixo índice de mobilidade da praia. Ao final da pesquisa o segmento apresentou um ganho de $43,12 \mathrm{~m}^{3} / \mathrm{m}$, embora o valor total de sedimentos transportados seja um dos mais baixos dos pontos de perfil, $\mathrm{Vt}=510$ $\mathrm{m}^{3} / \mathrm{m}$ (Tab. 1).

Tabela 1. Índices morfométriços relativos às estações de levantamento.

\begin{tabular}{|c|c|c|c|c|c|c|c|c|}
\cline { 2 - 9 } \multicolumn{1}{c|}{} & ATAFONA & SCDANTAS & F.AÇÚ & FSTOMÉ & BFURADO & PM-4 & CARAPEBÚS & CABIÚNAS \\
\hline $\mathrm{N}^{\circ} \mathrm{de}$ Perfis & 20 & 23 & 24 & 24 & 25 & 24 & 20 & 13 \\
\hline $\mathrm{Gd}(\mathrm{mm} / \mathrm{fi})$ & $0,420 / 1,2$ & $0,720 / 0,45$ & $0,670 / 0,62$ & $1,13 /-0,18$ & $1,09 /-0,15$ & $1,01 / 0$ & $1,2 /-0,25$ & $1,22 /-0,25$ \\
\hline $\mathrm{Ws}(\mathrm{cm} / \mathrm{s})$ & 7,5 & 14 & 13 & 20 & 19,5 & 19 & 20 & 20 \\
\hline $\mathrm{Hb}(\mathrm{m})$ & 1 & 1 & 1 & 1 & 1 & 1 & 1 & 1 \\
\hline $\mathrm{T}(\mathrm{s})$ & 5 & 5 & $8 / 5$ & $8 / 5$ & 8 & 8 & 8 & 8 \\
\hline$\Omega$ & 2,6 & 1,4 & $0,9 / 1,5$ & $0,62 / 1$ & 0,64 & 0,65 & 0,63 & 0,63 \\
\hline $\mathrm{Grad}$ & $1: 11$ & $1: 8$ & $1: 7$ & $1: 7$ & $1: 6$ & $1: 6,5$ & $1: 6,5$ & $1: 6,5$ \\
\hline $\tan \beta$ & 0,09 & 0,13 & 0,142 & 0,142 & 0,165 & 0,153 & 0,150 & 0,152 \\
\hline$\Omega \operatorname{tcórico~}$ & 2,7 & 1,33 & 1,12 & 1,12 & 0,83 & 0,96 & 1 & 0,98 \\
\hline$\gamma \mathrm{b}(\mathrm{m})$ & 150 & 96 & 100 & 106 & 73 & 76 & 32 & 56 \\
\hline$\sigma \gamma \mathrm{b}$ & 19 & 6 & 16 & 13 & 8 & 6 & 3 & 4 \\
\hline $\mathrm{CV}$ & 0,13 & 0,06 & 0,16 & 0,12 & 0,11 & 0,08 & 0,08 & 0,07 \\
\hline$\delta \mathrm{l}(\mathrm{m})$ & -37 & -2 & +3 & +10 & +3 & -3 & +10 & +4 \\
\hline $\mathrm{VV}\left(\mathrm{m}^{3} / \mathrm{m}\right)$ & -27 & 43 & -16 & 145 & 4 & 40 & 17 & 8 \\
\hline $\mathrm{Vg}\left(\mathrm{m}^{3} / \mathrm{m}\right)$ & 1300 & 510 & 530 & 1240 & 505 & 445 & 180 & 160 \\
\hline
\end{tabular}

$\mathrm{Gd}(\mathrm{mm})$-granulometria

$\mathrm{Hb}$ - altura da onda na arrebentação $(\mathrm{m})$

T-período das ondas (s)

Ws-velocidade de queda do grão, obtido em Open, 1994

$\Omega=\mathbf{H b} / \mathbf{T}$.Ws (Dean, 1973)

Grad.- gradiente da face de praia

$\operatorname{tg} \beta$ - função do gradiente da face de praia

$\Omega_{\text {teórico }}=\mathbf{0 , 0 2 2 5} / \mathbf{t a g} \beta^{2}$ (Klein, 1997) $\gamma b$-largura média da praia

$\sigma \gamma b$ - índice de mobilidade da praia

$\mathrm{CV}$ - índice de mobilidade do pós-praia(coeficiente de variação $\sigma \gamma b / \gamma b$ )

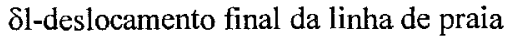

Vv-variação relativa final de volume acima do datum

$\mathrm{Vg}$ - volume total de sedimentos transportados durante 0 levantamento (gross volume) 

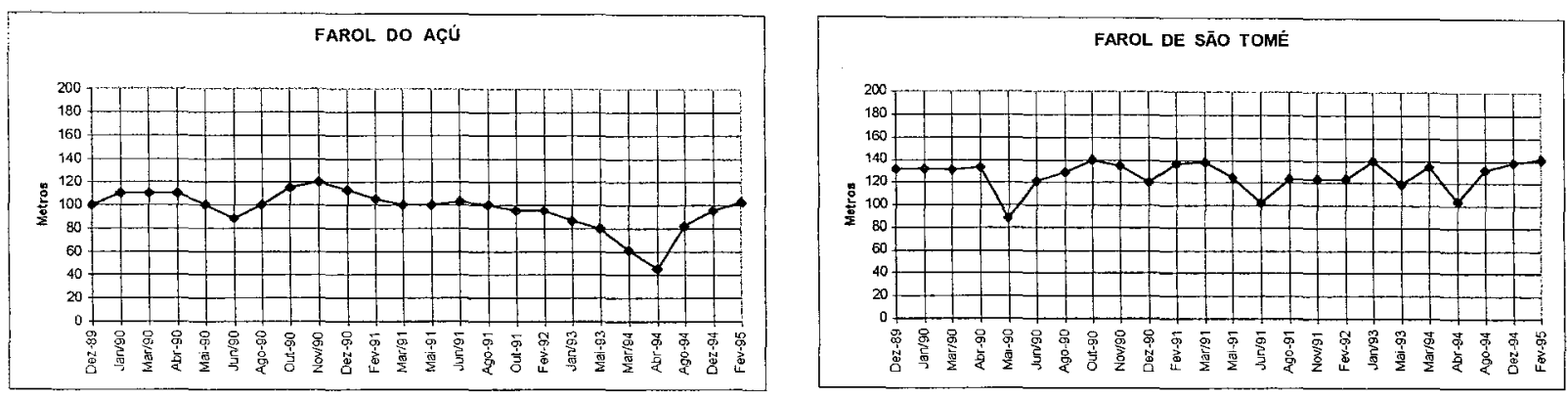

Fig. 8. Gráfico da variação temporal da largura da praia em Farol do Açú e Farol de São Tomé.

Em função da direção da linha de costa, estima-se que Saco Dantas esteja sob as mesmas condições de ondas estimadas para Atafona, entretanto, 0 fator granulometria parece estar controlando as variações temporais neste setor. Isto é perfeitamente notável no cálculo de $\Omega$, apresentando um valor de 1,4. Da mesma forma, a granulometria condiciona o gradiente da face de praia e o valor encontrado para $\Omega$ teórico foi de 1,33 .

Portanto, a praia em Saco Dantas pode ser descrita como intermediária, ressaltando que a granulometria está controlando as variações temporais do perfil, tendo em vista não só o baixo índice de mobilidade, mas também as características morfodinâmicas distintas em relação a Atafona.

\section{Farol do Açú}

O perfil neste ponto tem uma largura média de $100 \mathrm{~m}$, sendo morfologicamente semelhante ao de Saco Dantas, com um pós-praia plano com declive suave, marcado por uma crista de berma elevada seguida por uma face de praia íngreme, com declive de 1:7 $\left(8^{\circ}\right)$ e composta por areia grossa $(0,670$ $\mathrm{mm} / 0,6 \phi$ ). Tipicamente, os perfis erosivos que se desenvolvem durante os períodos de tempestade, são caracterizados por um recuo da face de praia, que mantém seu alto gradiente, seguido de uma crista de berma.

A principal característica do perfil de Farol do Açú é seu alto índice de mobilidade, $\sigma \gamma b=16$ (Fig. 8), sem que apresente tendências erosivas notáveis como em Atafona. Pelo gráfico da variação temporal dos perfis (Fig. 9), fica evidente que esta grande mobilidade do perfil reflete uma instabilidade da praia face ao aumento da energia hidrodinâmica. $\mathrm{O}$ alto índice de mobilidade do pós-praia $(\mathrm{CV}=0,16$ $16 \%$ ) reflete ainda, esta condição de instabilidade do perfil acarretando erosão.

Outra curiosidade, é que embora apresente um alto índice de mobilidade, o volume total de sedimento transportado é da ordem de 570 $\mathrm{m}^{3} / \mathrm{m}$, o que comparativamente é um valor baixo (Tab. 1).

Antes de se fazer uma análise da classificação morfodinâmica da praia em Farol do Açú, é importante ressaltar que a mesma está localizada geograficamente no Cabo de São Tomé onde o litoral ao norte (descrito em Atafona e Saco Dantas) com direção NNW-SSE sofre uma inflexão para SW-NE.

Baseando-se na declividade da face de praia, o valor modal calculado para $\Omega$ teórico foi de $1,12, \operatorname{logo}$ a análise de todos os parâmetros nos leva a uma classificação morfodinâmica de intermediária à refletiva, ressaltando o alto índice de mobilidade deste perfil, que reflete a instabilidade de praias refletivas frente a um aumento na energia das ondas.

\section{Farol de São Tomé}

O perfil em Farol de São Tomé, à semelhança dos dois anteriores, apresenta um póspraia com declive suave, porém, caracterizado por uma maior variação vertical e associado com cristas de praias. A largura média do perfil é de $106 \mathrm{~m}$ e geralmente ocorre uma crista de berma seguida por uma face de praia íngreme com gradiente de 1:7 $\left(8^{\circ}\right)$ composta de areia grossa à muito grossa $(1,13$ $\mathrm{mm} /-0,18 \phi)$.

A partir do envelope de variação temporal dos perfis (Fig. 9), nota-se que a exemplo do perfil em Farol do Açú, o perfil de Farol de São Tomé apresenta grande instabilidade com períodos de erosão e deposição, refletindo em um alto índice de mobilidade $\sigma \gamma \mathrm{b}=13$, seguido de um índice igualmente elevado da mobilidade do pós-praia $(\mathrm{CV}=0,12-12 \%)$. $\mathrm{O}$ gráfico de variação da largura do perfil (Fig. 9) evidencia esta mobilidade, ressaltando que o perfil sofreu fases de recuo e avanço, sem que fosse notada uma tendência marcante. Entretanto, analisando cuidadosamente o gráfico, observa-se uma pequena tendência residual de avanço da linha de praia em torno de $10 \mathrm{~m}$. 


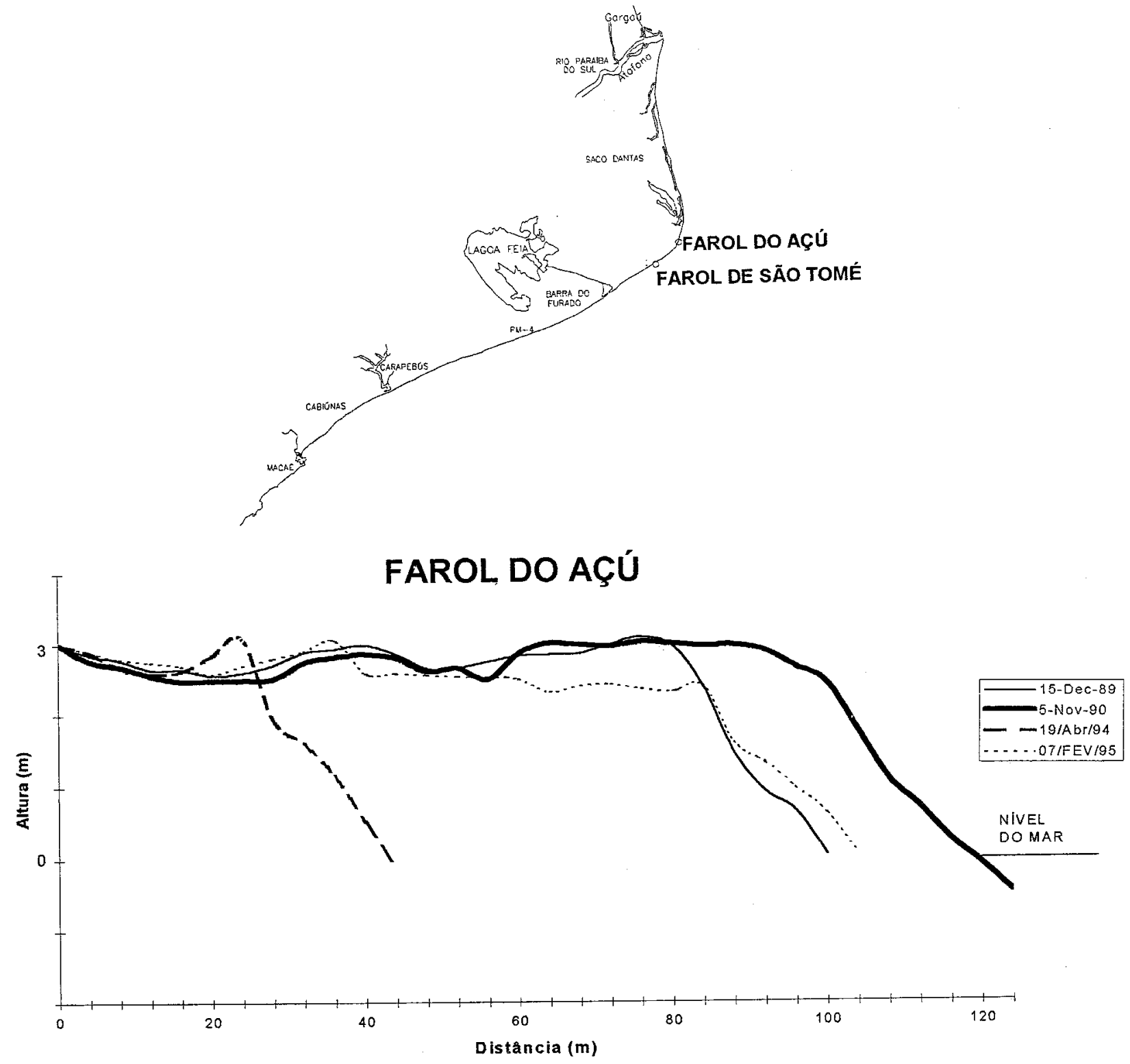

FAROL DE SÃO TOMÉ

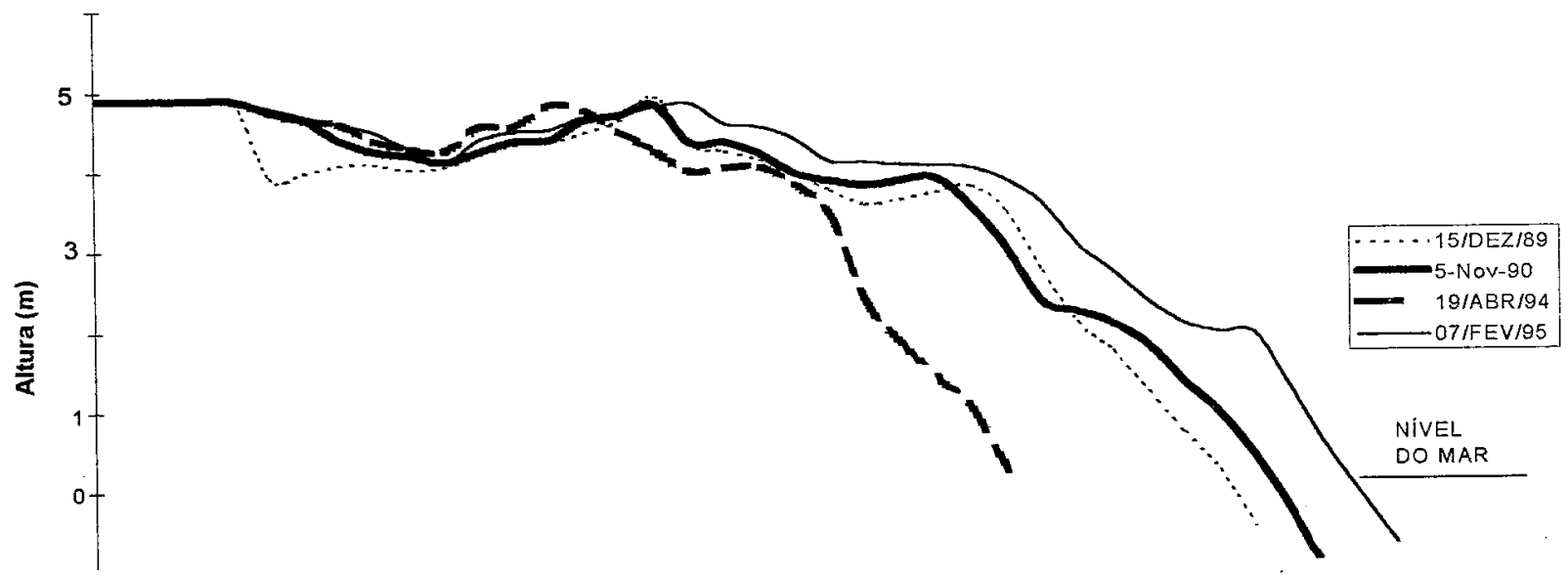

Fig. 9. Envelope de variação temporal dos perfis de praia em Farol do Açú e Farol de São Tomé. 
A variação morfológica dos perfis durante o levantamento, revela uma característica bastante similar ao que foi observado em Farol do Açú, quanto ao não desenvolvimento de perfis típicos de tempestade ou inverno. Os perfis erosivos em farol de São Tomé, são marcados por uma face de praia íngreme seguida de uma alta crista de berma. Esta característica é muito provavelmente controlada pela granulometria grossa do sedimento

As características descritas para o perfil de praia em Farol de São Tomé classificam esta praia como intermediária à refletiva, porém, assim como em Farol do Açú, é um perfil de alta mobilidade que se apresenta bastante instável frente a eventos de alta energia.

\section{Barra do Furado}

Quanto à morfologia, o perfil da Barra do Furado já começa a apresentar características distintas dos perfis anteriores, a começar pela altura do cordão litorâneo, em torno de $5,5 \mathrm{~m}$, enquanto que nos perfis de Saco Dantas e Farol do Açú o cordão alcança cerca de $3 \mathrm{~m}$ de altura. Observa-se um perfil mais plano, com largura média de $73 \mathrm{~m}$ e um póspraia estreito, porém com uma face de praia íngreme com declive de $1: 6\left(9,4^{\circ}\right)$ e composta por areia grossa à muito grossa $(1,09 \mathrm{~mm} /=0,15 \phi)$.

Quanto à mobilidade do perfil praial, o gráfico de variação temporal dos perfis (Fig. 10) indica uma praia moderadamente estável, com índice $\sigma \gamma b=8 \mathrm{e}$ com volume total de sedimentos transportados em torno de $505 \mathrm{~m}^{3} / \mathrm{m}$. As maiores variações morfológicas ocorrem em eventos isolados, provavelmente fortes frentes frias, provocando a erosão natural do perfil. $O$ índice de mobilidade do pós-praia $(\mathrm{CV}=0,11$ - 11\%) na Barra do Furado, pode ser considerado alto com valores próximos ao do Farol de São Tomé e de Atafona, corroborando assim, a tendência de erosão do pós-praia durante os eventos de alta energia (Tab. 1).

A curva de variação da largura do perfil praia (Fig. 11) corrobora o índice de mobilidade da linha de praia, relativamente baixo, e mostra uma tendência de aumento da largura da praia interrompida apenas durante dois eventos em junho/90 e abril/94.

Ao final do levantamento, observou-se uma tendência geral de ganho de volume sedimentar e avanço da linha de costa, entretanto o perfil se mostrou bastante instável frente a eventos de mais alta energia. Em função da configuração da linha de costa que apresenta uma direção SW-NE, o clima de ondas dominante passa a ser ondas de swell com períodos de $8 \mathrm{~s}$ e altura de quebra de $1 \mathrm{~m}$. O valor calculado para o parâmetro $\Omega$ foi de 0,64 , o que corresponde a condições morfodinâmicas extremamente refletivas.

A característica refletiva do perfil em Barra do Furado foi ainda corroborada pelo valor de $\Omega$ teórico $=0,83$. Logo, a característica morfológica distinta deste perfil e dos outros que compõem este segmento do litoral e que serão descritos a seguir, está associada à evolução geomorfológica da planície costeira.

\section{PM-4}

A praia em PM-4 apresenta um perfil parecido com a Barra do Furado, com o cordão litorâneo alcançando aproximadamente $5,5 \mathrm{~m}$ de altura e em média $76 \mathrm{~m}$ de largura., sendo caracterizado por uma crista de berma seguida de uma face de praia íngreme $\left(1: 6,5 / 8,7^{\circ}\right)$ composta de areia grossa à muito grossa $(1,01 \mathrm{~mm} / 0 \phi)$.

O gráfico de variação temporal do perfil e a curva de variação da largura da praia revelam uma baixa mobilidade do perfil, $\sigma \gamma \mathrm{b}=6$, quebrada apenas pelo forte processo erosivo causado durante um evento de alta energia em abril/94 (Figs 10 e 11, respectivamente). $\mathrm{O}$ indice $\mathrm{CV}$ também apresenta baixa mobilidade do pós-praia, com valor igual a $0,08(8 \%)$.

Quanto à classsificação morfodinâmica, o perfil em PM-4 é bastante similar ao de Barra do Furado, apresentando características refletivas expressas pelos valores de $\Omega=0,65$ e de $\Omega$ teórico modal de 0,96 .

\section{Carapebús}

O perfil em Carapebús à exemplo de Barra do Furado e PM-4, apresenta um cordão arenoso de 5 $\mathrm{m}$ de altura com largura média de $32 \mathrm{~m}$. Morfologicamente o perfil possui uma face de praia ingreme com declividade da ordem de 1:6,5 $\left(8,5^{\circ}\right)$ composta de areia grossa à muito grossa $(1.2 \mathrm{~mm} /$ $0,25 \phi)$.

Como mostram os gráficos de variação temporal e da largura dos perfis, a praia em Carapebús é caracterizada pelos baixos indices de mobilidade da linha de praia, $\sigma \gamma \mathrm{b}=3$ e do pós-praia (CV=0,08 - 8\%) (Figs 10-11),

Desta forma, como já vem sendo observado nos perfis ao longo deste trecho do litoral, a praia em Carapebús apresenta um baixo índice de mobilidade e valores de $\Omega=0,63$ e $\Omega$ teórico modal $=1$, que apontạm à condições morfodinâmicas refletivas.

\section{Cabiúnas}

Morfologicamente, o perfil em Cabiủnas é similar ao de Carapebús, sendo caracterizado por 

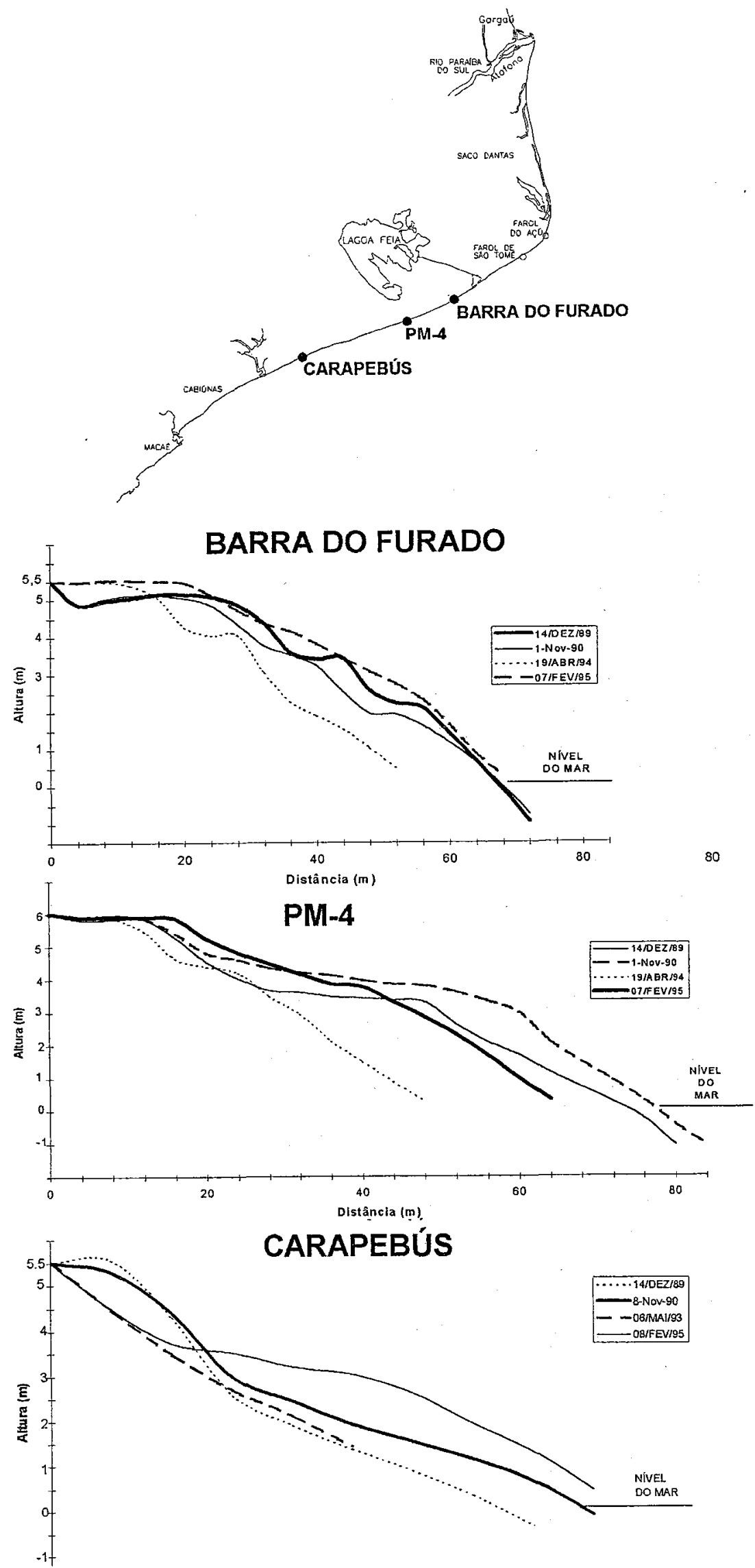

Fig. 10. Envelope de variação temporal dos perfis de praia em Barra do Furado, PM-4 e Carapebús. 

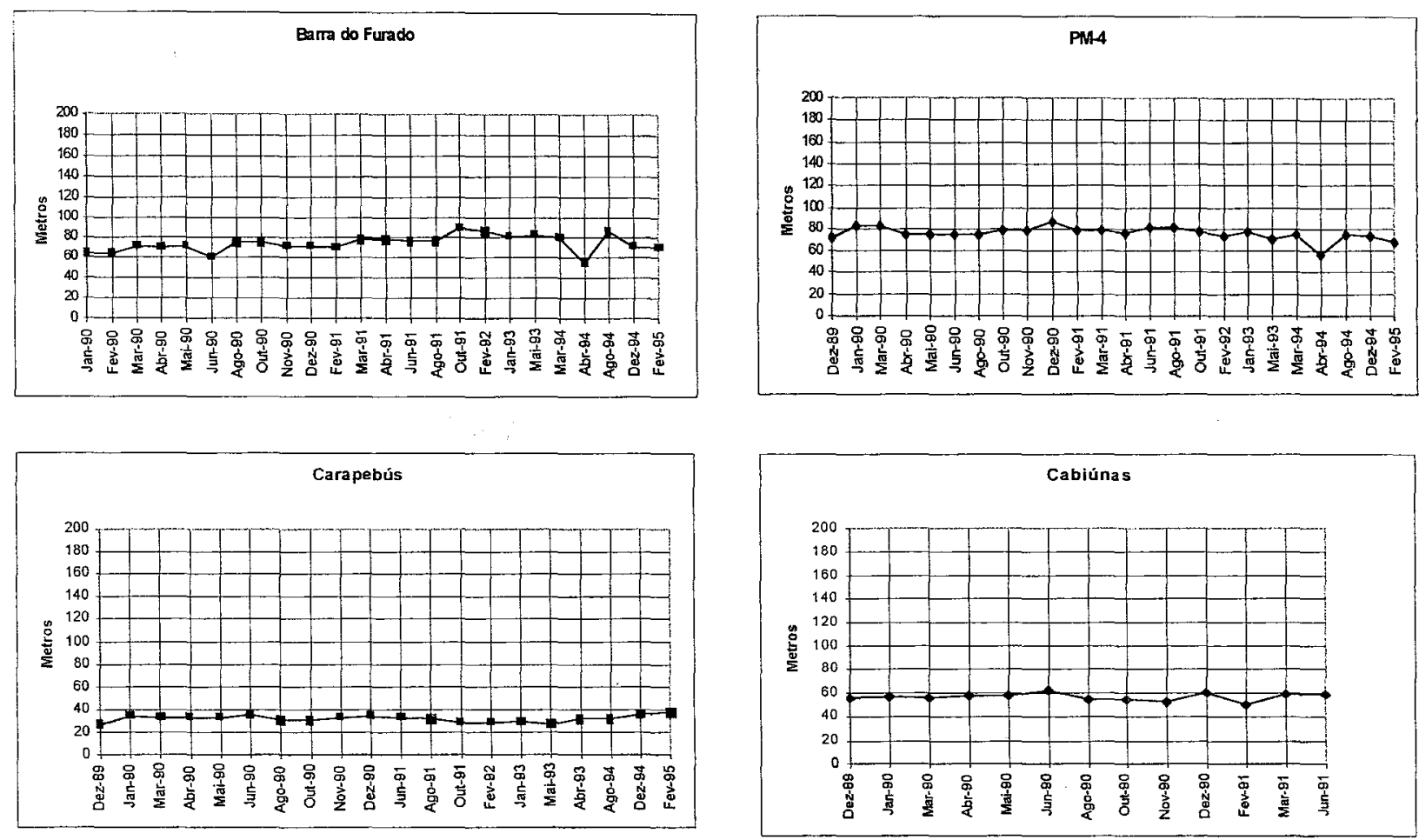

Fig. 11. Gráfico da variação temporal da largura da praia em Barra do Furado, PM-4, Carapebús e Cabiúnas.

uma crista elevada $(5 \mathrm{~m})$ que marca o topo do cordão litorâneo. A largura média da praia é de 56 $\mathrm{m}$, com uma face de praia apresentando declive de $1: 6,5\left(8,6^{\circ}\right)$, sendo composta de areia grossa à muito grossa $(1,22 \mathrm{~mm} /-0,25 \phi)$.

O gráfico de variação da largura da praia (Fig. 11) denota a característica de baixa mobilidade do perfil, evidenciada ainda pelos índices de mobilidade da linha de praia e do pós-praia $(\sigma \gamma b=4$ e $\mathrm{CV}=7 \%$ ).

A caracterização do perfil em Cabiúnas apresentou uma desvantagem em relação a todos os demais em virtude da mudança de posição do levantamento topográfico, o que reduziu a uma amostragem de 13 perfis.

Entretanto, é possível caracterizar a praia dentro do domínio morfodinâmico refletivo com $\Omega=$ 0,63 e $\Omega$ teórico modal $=0,98$.

\section{Discussão}

A análise morfológica dos perfis nos evidencia que o litoral apresenta uma importante variação espacial na morfologia das praias, marcada pela distinção dos perfis ao sul e ao norte do Cabo São Tomé, e ainda pelo perfil peculiar de Atafona, mostrados na Figura 12. Ainda do ponto de vista morfológico, a relação entre granulometria $\mathrm{x}$ declividade da face de praia ao longo do litoral, está representada no diagrama da Figura 13, mostrando que de norte para sul há uma tendência de aumento da granulometria das praias, seguida pelo aumento do grau de declividade da face de praia.

A variação espacial da morfologia das prais ao longo do litoral, reflete não só condições distinatas do clima de ondas, mas se enquadra também no contexto evolutivo da planície costeira. Ao norte do Cabo de São Tomé, os perfis de Atafona e Saco Dantas fazem parte do sistema progradante formado pela planície de cristas de praia do rio Paraíba do Sul, sendo caracterizados por extensos perfis com cristas de praia e/ou dunas associadas. Por outro lado, ao sul do Cabo de São Tomé os perfis são marcados por um estreito cordão arenoso com crista alcançando 5,5 a $6 \mathrm{~m}$ de altura. Estes perfis representam um cordão arenoso transgressivo, indicando uma linha de costa retrogradante.

Os perfis de Farol do Açú e Farol de São Tomé são similares ao de Saco Dantas, devido aos mesmos estarem situados na região do Cabo de São Tomé, que apresenta características progradantes distintas, provavelmente em função da convergência de deriva litorânea. Vale destacar o perfil de Atafona, que apresenta uma morfologia característica, com valores de granulometria e declividade bem inferio res aos dos demais perfis. Esta característica particular para Atafona, provavelmente, se dá devido 


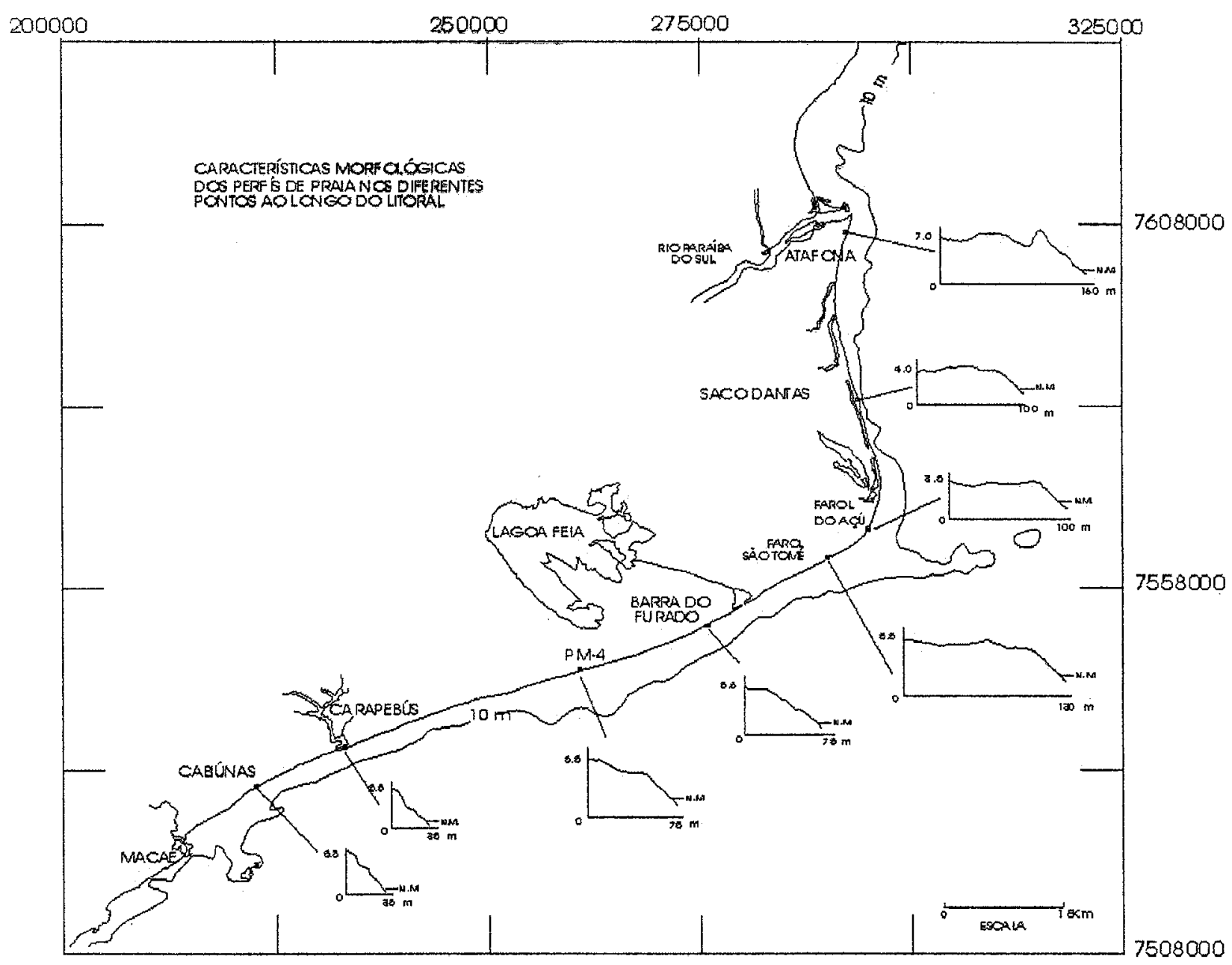

Fig. 12. Variação espacial da morfologia dos perfis ao longo do litoral estudado. (Projeção UTM, Meridiano central -39).

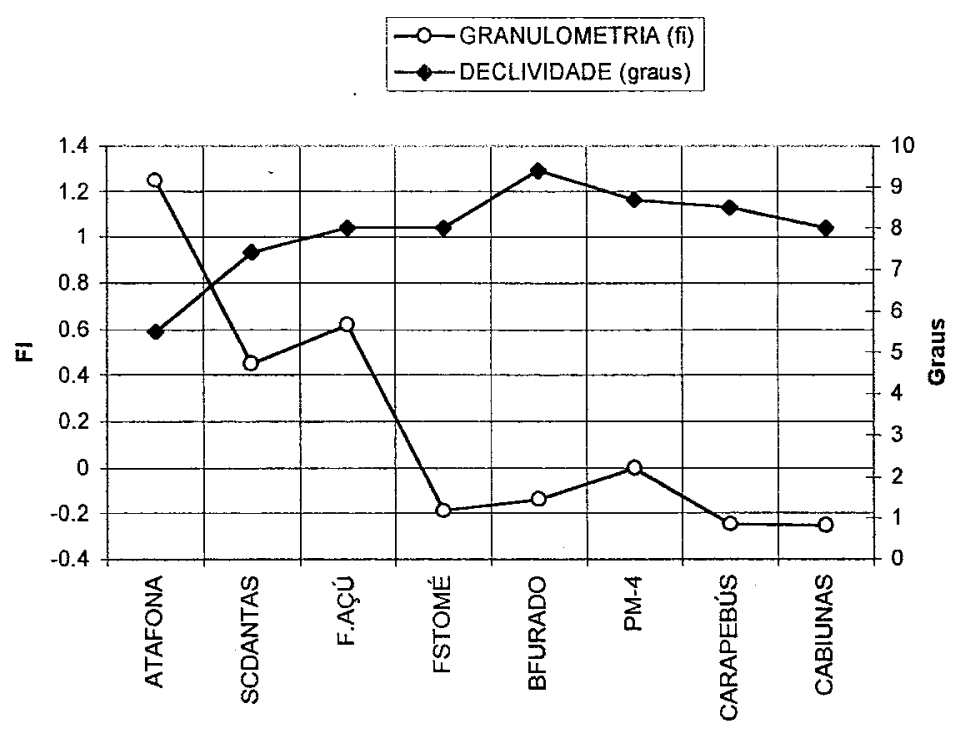

Fig. 13 - Gráfico mostrando a relação granulometria $\mathrm{X}$ declividade face de praia ao longo do litoral. 
à influência da vazão e da carga sedimentar do rio Paraíba do Sul, bem como da erosão frontal das dunas que alimentam a praia com sedimentos de menor granulometria.

Logo, a análise morfodinâmica dos perfis de praia, permitiu o reconhecimento de quatro setores de comportamento morfodinâmico distintos que são descritos abaixo e representados na Figura 14.

\section{Atafona/Foz do Rio Paraíba do Sul - Perfil Atafona}

- Planície progradante de cristas de praia do rio Paraíba do Sul associada ao lobo deltaico do mesmo rio e a uma extensa plataforma continental com baixos gradientes.

- O limite norte da planície costeira registra uma série de discordâncias evidenciando processos erosivos ao longo de sua evolução. Os resultados mostraram um taxa média de erosão de 7,5 $\mathrm{m} / \mathrm{ano}$, e uma taxa mínina de progradação da planície, ao longo de sua evolução, de $4 \mathrm{~m} / \mathrm{ano}$, podendo alcançar até $7 \mathrm{~m} /$ ano nas proximidades da desembocadura.

- Zona de surfe extensa com ondas deslizantes ou progressivas e mais de duas zonas de arrebentação.

- Estágio morfodinâmico intermediário, $\Omega=2,6$ e Steórico $=2,7$.

- $\quad$ Alto índice de mobilidade, $\sigma \gamma b=19$

\section{Sul de Atafona ao Cabo de São Tomé - Perfil Saco Dantas}

- Planície progradante de cristas de praia do rio Paraíba do Sul associada a uma extensa plataforma continental com baixos gradientes (1:2200, até $30 \mathrm{~m}$ de profundidade) e paleocanal associado, sendo portanto, uma importante fonte supridora de sedimentos.

- Taxa de progradação durante a evolução da planície: $2,6 \mathrm{~m} / \mathrm{ano}$.

- Zona de surfe extensa com ondas deslizantes ou progressivas e mais de duas zonas de arrebentação.

- Estágio morfodinâmico intermediário, $\Omega=1,4$ e $\Omega$ teórico $=1,33$.

- Baixo índice de mobilidade, $\sigma \gamma b=6$

\section{Cabo de São Tomé - Perfis Farol do Açu e Farol São Tomé}

- Planície progradante estreita associada ao Banco Submarino de São Tomé.
- Ponto de inflexão do litoral e provável região de convergência de deriva litorânea.

- Taxa de progradação: 2 m/ano.

- Ondas deslizantes ou progressivas e mergulhantes, com uma a duas zonas de arrebentação.

- Estágio morfodinâmico intermediário-refletivo, $\Omega=1 \Omega$ teórico=1,12.

- $\quad$ Alto índice de mobilidade, $\sigma \gamma b=13-16$

Cabo de São Tomé a Cabiúnas - Perfis Barra do Furado, PM-4, Carapebús e Cabiúnas

- Litoral retrogradante caracterizado por um cordão arenoso transgressivo, associado a uma plataforma continental com gradientes elevados (1:560 até $38 \mathrm{~m}$ de profundidade).

- Zona de surfe estreita com ondas mergulhantes e apenas uma zona de arrebentação.

- Estágio morfodinâmico refletivo: $\Omega=0,65$ e $\Omega$ teórico $=0,9$.

- $\quad$ Baixo indice de mobilidade, $\sigma \gamma b=3-8$

\section{Conclusão}

Quanto à caracterização morfodinâmica, pode-se dizer que a metodologia aplicada aos perfis praiais, bem como o cálculo dos parâmetros morfométricos, proporcionaram uma análise comparativa e diagnóstica de setores com diferentes índices de mobilidade, respostas morfológicas a eventos de alta energia, relações granulometria $x$ declividade da face de praia e características do clima de ondas.

Ainda sobre os parâmetros morfométricos, é importante destacar que a aplicação do cálculo de $\Omega$ teórico proposto por Klein (1997), foi bastante significativa neste trabalho, tendo em vista que durante o levantamento dos perfis não houve coleta de dados de ondas. Logo, o dado mais consistente, seria o levantamento topográfico.

Portanto, considerando que a morfologia da praia é função do clima de ondas, do tipo de sedimento e do estágio morfodinâmico imediatamente anterior (Wright \& Short, 1984), a declividade da face de praia vai estar condicionada à energia das ondas $(\mathrm{Hb}$ e $\mathrm{T}$ ) e granulometria do sedimento, que são as variáveis utilizadas por Dean (1973) para o cálculo de $\Omega$. A comparação destes dois parâmetros neste trabalho foi bastante satisfatória, entretanto, vale lembrar que $\Omega$ foi calculado a partir de dados médios, enquanto que $\Omega$ teórico é um valor modal. 


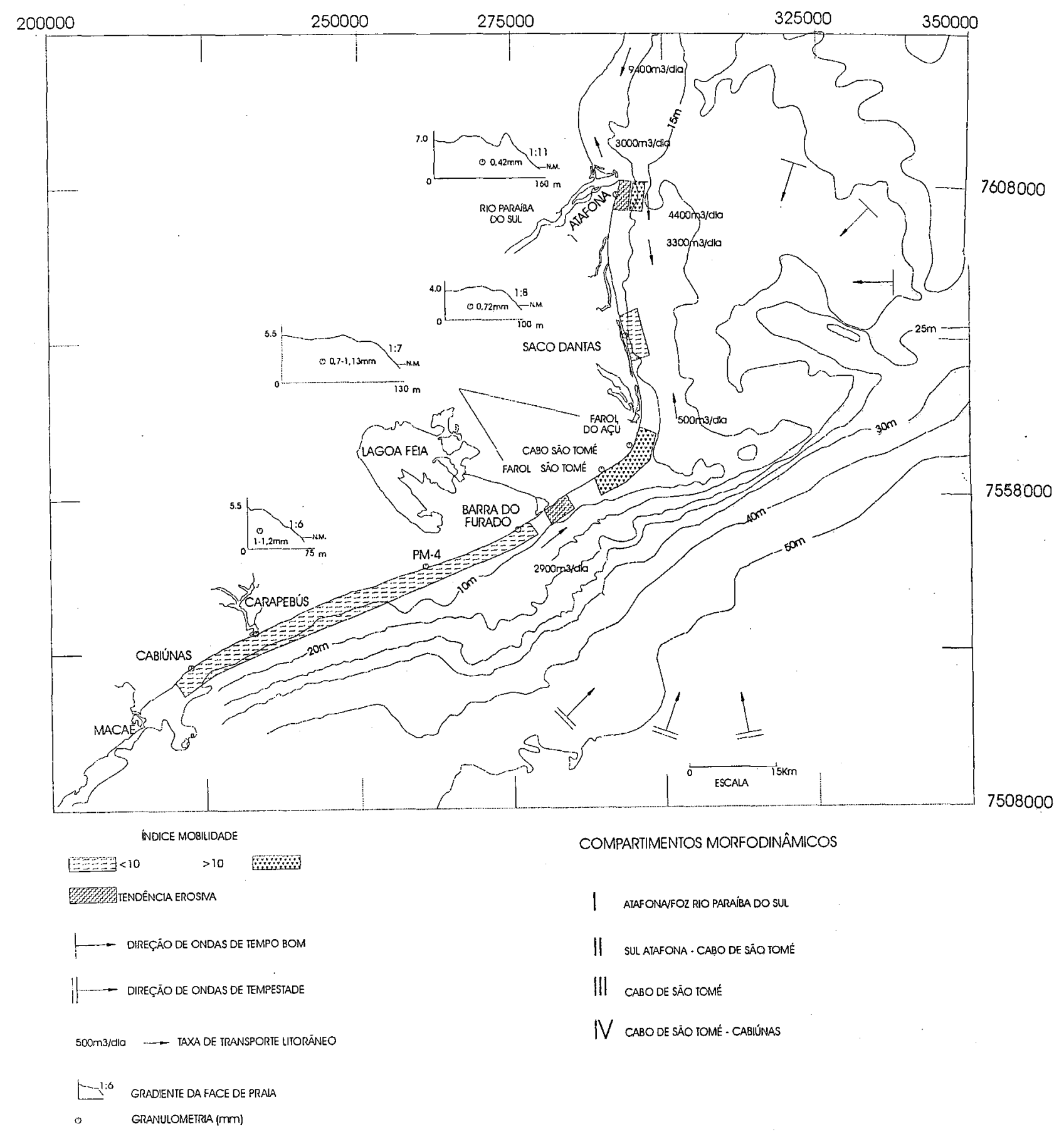

Fig. 14. Mapa de comportamento morfodinâmico do litoral, ressaltando os principais parâmetros morfométricos e hidrodinâmicos que caracterizam os diferentes setores morfodinâmicos do litoral. (Projeção UTM, Meridiano central -39). 


\section{Agradecimentos}

Os autores agradecem à Gerência de Geologia Marinha (GEOMAR) da PETROBRÁS S/A, por ter cedido todos os dados referentes aos levantamentos topográficos de praia realizados ao longo do litoral norte fluminense, e que foram utilizados como parte da Dissertação de Mestrado do autor, sob a orientação do Doutor Cleverson G. Silva, no Programa de Pósgraduação em Geologia e Geofísica Marinha, Dept. de Geologia-UFF.

$\mathrm{Da}$ mesma forma, agradecemos à GGG Consultoria Ltda, que gentilmente forneceu o mapa batimétrico da plataforma continental da área estudada.

\section{Referências bibliográficas}

Alves, E. C. \& Ponzi, V. R. A. 1984. Características morfológico-sedimentares da plataforma continental e talude superior da margem continental sudeste do Brasil. In: CONGRESSO BRASILEIRO DE GEOLOGIA, 33. Rio de Janeiro, 1984. Anais. Rio de Janeiro, SBG, 4:1629-1642.

Bastos, A. C. 1994. Estudo da variação morfológica a partir de perfis de praia em Piratininga, NiteróiRJ. Monografia final. Universidade Federal do Rio de Janeiro, Departamento de Geologia. 120p.

Bastos, A. C. 1997. Análise morfodinâmica e caracterização de processos erosivos ao longo do litoral norte fluminense, entre Atafona e Cabiúnas, RJ, Brasil. Dissertação de mestrado. Universidade Federal Fluminense, Departamento de Geologia. 135p.

Birkemeier, W. A. 1985. A User's guide to ISRP: The Interactive Survey Reduction Program. Instruction Report CERC-84-1. Mississippi, Coastal Engineering Research Center. 10lp.

Bush, D. M. \& Pilkey, O. H. 1994. Mitigation of hurricane property damage on barrier islands:: A geological view. In: Finkl Jr., C. W. ed. Coastal hazards, perception, susceptibility and mitigation. Flórida, CERF. p.311-326.

Calliari, L. J. \& Klein, A. H. F. 1993. Características morfodinâmicas e sedimentológicas das praias oceânicas entre Rio Grande e Chuí, RS. Rev. Pesquisas, 20:48-56.
Carter, R. W. G. \& Woodroffe, C. D. 1995. Coastal evolution: late quaternary shoreline morphodynamics. Cambridge, Cambridge University Press. 255p.

Cassar, J. C. M. \& Neves, C. F. 1993. Aplicação das rosas de transporte litorâneo à costa nortefluminense. RBE, 11:81-103.

Dean, R. G. 1973. Heuristic models of sand transport in the surf zone. In: CONFERENCE ON ENGINEERING DYNAMICS IN THE SURF ZONE. Sydney, 1973. Proceedings. Sidney, N.S.W. p.208-214.

Dominguez, J. M. L.; Bittencourt, A. C. S. P. \& Martin, L. 1983. O papel da deriva litorânea de sedimentos arenosos na construção das planícies costeiras associadas a desembocaduras dos rios São Francisco (SE/AL), Jequitinhonha (BA), Doce (ES) e Paraíba do Sul (RJ). Rev. Bras. Geoc., 13(3):98-105.

Gornitz, V. M.; Daniels, R. C.; White, T. W. \& Birdwell, K. R. 1994. The development of a coastal risk assessment database: Vulnerability to sea-level in the U.S. southeast. In: Finkl Jr., C. W. ed. Coastal hazards, perception, susceptibility and mitigation. CERF. $371 \mathrm{p}$.

Klein, A. H. F. 1997. Um método indireto para a determinação do estágio morfodinâmico de praias oceânicas arenosas. In: CONGRESSO DA ASSOCIAÇÃO BRASILEIRA DE ESTUDOS QUATERNÁRIO, 6. Curitiba, 1997. Resumos expandidos. São Paulo, ABEQUA. p.76-78.

Martin, L.; Suguio, K.; Flexor, J. M.; Dominguez, J. M. L. \& Azevedo, A. E. G. 1984a. Evolução da planície costeira do rio Paraíba do Sul (RJ) durante o Quaternário: influência das flutuações do nível do mar. In: CONGRESSO BRASILEIRO DE GEOLOGIA, 33. Rio de Janeiro, 1984. Anais. Rio de Janeiro, SBG, 1:8497.

Martin, L.; Suguio, K.; Flexor, J. M.; Tessler, M. G. \& Eichler, B. B. 1984b. Significado geológico das variações dos graus de arredondamento das areias holocênicas da planície costeira do rio Paraíba do Sul (RJ). In: CONGRESSO BRASILEIRO DE GEOLOGIA, 33. Rio de Janeiro, 1984. Anais. Rio de Janeiro, SBG, 1:119-132. 
Muehe, D. \& Corrêa, C. H. T. 1989. Dinâmica de praia e transporte de sedimentos na restinga de Maçambaba, RJ. Rev. Bras. Geoc., 19:387-392.

Short, A. D. 1981. Beach response to variations in breaker height. In: INTERNATIONAL CONFERENCE COASTAL ENGINEERING, 17. Sidney, Australia, 1980. Proceedings. New York, American Society of Civil Engineers. p.10161035.

Short, A. D. 1984. Beach and nearshore facies: southeast Australia. In: Greenwood, B. \& Davis Jr., R. A. eds Hydrodynamic and sedimentation in wave-dominated coastal environments. Mar. Geol., $60(1 / 4): 261-282$.

Short, A. D. 1993. Beaches of the NSW coast. Sydney, Australian Beach Safety and Management Program. 358p.

Short, A. D. \& Hesp, P. A. 1982. Wave, beach and dune interactions in Southeastern Australia. Mar. Geol., 48: 259-284.

Silva, C. G. 1987. Estudo da evolução geológica e geomorfológica da região da Lagoa Feia, RJ. Dissertação de mestrado. Universidade Federal do Rio de Janeiro, Departamento de Geologia.116p.

Silva, C. G.; Silva, M. A. M.; Alves, E. C. \& Sichel, S. E. 1997. Compartimentação tectônica entre as bacias de Campos e Santos: O papel da zona de fratura do Rio de Janeiro e do magmatismo do Alto de Cabo Frio. Relatório Interno, 6593043300. Rio de Janeiro, PADCT/FINEP/ UFF. 65930433-00.

Souza, M. H. S. 1988. Clima de ondas ao norte do Estado do Rio de Janeiro. RJ. Dissertação de mestrado. Universidade Federal do Rio Janeiro, COPPE. 181p.
Wright, L. D. \& Short, A. D. 1984. Morphodynamic variability of surf zones and beaches: A synthesis. Mar. Geol., 56(1-4):93-118.

Wright, L. D. \& Thom, B. G. 1977. Coastal depositional landforms: A morphodynamic approach. Progr. phys. Geogr., 1:412-459.

Wright, L. D.; Chappell, J.; Thom, B. G.; Bradshaw, M. P. \& Cowell, P. 1979a. Morphodynamics of reflective and dissipative beach and inshore systems: Southeastern Australia. Mar. Geol., 32(1-2):105-140.

Wright, L. D.; Chappell, J. \& Thom, B. G. 1979b. Morphodynamics variability of high energy beaches. In: INTERNATIONAL CONFERENCE ON COASTAL ENGINEERING. 16. Hamburg, 1979. Proceedings. New York, American Society of Civil Engineers. p.1180-1194.

Wright, L. D.; Short, A. D. \& Nielsen, P. 1982. Morphodynamics of high energy beaches and surf zones: a brief synthesis. University of Sidney, Coastal Studies Unit Technical Report, 82/5. 64p.

(Manuscrito aceito 04 setembro 1998; revisado 15 dezembro 1998; aceito 24 abril 2000) 